\title{
CALCIFIED FOCI WITHIN THE THORAX OF ENGLISH CHILDREN
}

\author{
BY \\ BRIAN C. THOMPSON* \\ From the Ealing Chest Clinic, Middlesex
}

The demonstration by radiology of calcified foci in the lung or intrathoracic lymph nodes has usually been accepted as evidence of past infection with tuberculosis. It has now been shown in certain parts of the United States that large numbers of persons exhibiting such foci fail to react to the intracutaneous injection of tuberculin but do give a positive reaction to other antigens, notably those of Coccidioides immitis and Histoplasma capsulatum, infections now believed to be endemic in those regions (Christie and Petersen, 1945; Palmer, 1945; High and others, 1947).

In the light of this discovery it seems necessary to consider what significance should be attached to the presence of calcified foci in England. A previous study (Thompsorr, 1947), which dealt with some aspects of primary tuberculous infection in children, referred briefly to the incidental detection of such foci. This point will now be examined in more detail.

\section{Study at the Ealing Chest Clinic}

Of 1,476 children who attended the Ealing Chest Clinic in the years 1942 to $1945,1,050$ came as contacts of a tuberculous associate, and 426 were referred by private doctors on account of suggestive symptoms but without any known contact with tuberculosis. Routine examination included a tuberculin patch test and, if this were negative, an intradermal injection equal to $0.1 \mathrm{ml}$. of $1: 100$ Old Tuberculin, though this complete test was not achieved in all cases. Radiographs of the chest were made in all cases except some of the younger contact children who gave negative reactions to the tuberculin test. No special technique was employed, and, in order to avoid the common error of over-diagnosis, the diagnosis of calcified lesions was made only when it appeared obvious. The proportion of cases in which calcified lesions were diagnosed is therefore an underestimate of their true incidence.

Chest radiographs of 1,100 children were made ; 105 of these showed calcification. This occurred

\footnotetext{
*The author is at present working at the Dunedin Hospital, New Zealand.
}

as nodules in the lung field in 18 cases, as localized lesions in the hilum (that is, in lymph nodes of the tracheo-bronchial-pulmonary group) in 21 cases, and as a combined nodule-plus-lymph-node manifestation (primary complex) in 66 cases. In only 4 cases were the lung nodules other than single: each of these had 2 nodules in the lung field with associated calcification at the hilum. In the other 80 cases with a single parenchymal nodule, this nodule was situated as shown in Table I.

TABLE I

SITE OF CALCIFIED PULMONARY FOCUS IN EIGHTY CHILDREN

\begin{tabular}{cc|c|c}
\hline & & Right & Left \\
\hline Upper third & $\ldots$ & 17 & 7 \\
Middle third & $\ldots$ & 19 & 10 \\
Lower third & . & 17 & 10 \\
\hline Total & $\ldots$ & 53 & 27 \\
\hline
\end{tabular}

It is apparent that the right lung was affected twice as frequently as the left ; otherwise the three zones of the lung field were about equally represented. This confirms the findings at autopsy of most observers from Ghon onwards (Rich, 1944) of the site of the primary tuberculous

TABLE II

CALCIFICATION RELATED TO TUBERCULIN SENSITIVITY

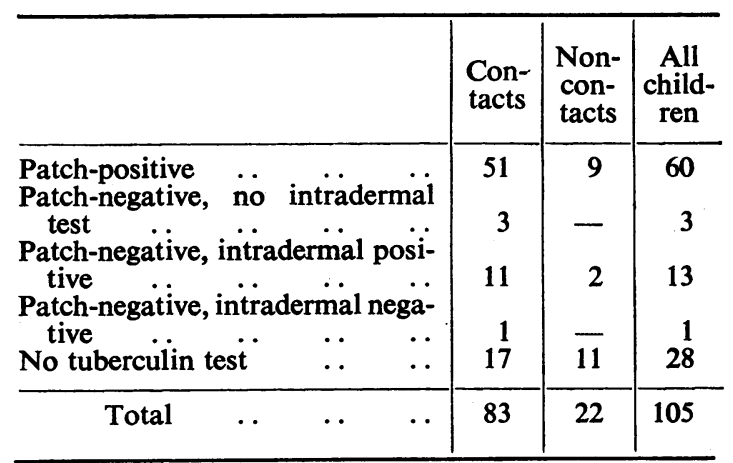


complex and of the usually single nature of its pulmonary component (Blacklock, 1936).

The relation of calcified lesions to tuberculin sensitivity is shown in Table II. Calcified foci were seen only in 1 case with a negative intradermal tuberculin test, and in 3 cases negative to the patch test but not confirmed intradermally. This suggests (1) that such calcification is in fact a tuberculous manifestation, and (2) that reversion from tuberculin-positivity to negativity, indicating the death of all tubercle bacilli within the body (Feldman and Helmholz, 1945) was rare in this series.

Not one of the 182 children who were less than two years of age was found to manifest calcified

\section{TABLE III}

AGE DISTRIBUTION OF 1,476 CHILDREN EXAMINED AND OF 105 WITH INTRATHORACIC CALCIFIED LESIONS

\begin{tabular}{l|rr|r|r|r}
\hline & \multicolumn{4}{|c}{ Age group (years) } \\
\cline { 2 - 6 } & $0-4$ & $5-9$ & $10-13$ & Total \\
\hline Total examined &.. & 462 & 606 & 408 & 1,476 \\
Total with calcification & 10 & 46 & 49 & 105 \\
$\begin{array}{l}\text { Percentage with calcifica- } \\
\text { tion .. }\end{array} \quad .$. & 2.2 & 7.7 & 12.2 & 7.0 \\
\hline
\end{tabular}

lesions, though 42 of them were tuberculin-positive. As Brailey (1937) has demonstrated, calcium deposition in caseous lesions may take many months to become radiologically evident, so that a time-lag would here be expected.

TABLE IV

DISTRIBUTION OF CALCIFIED LESIONS AT VARIOUS AGE GROUPS IN CONTACT AND NON-CONTACT CHILDREN

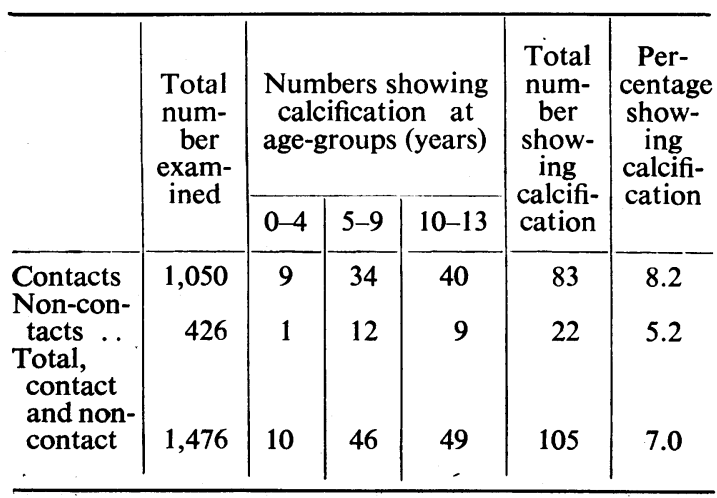

The age-distribution of the 105 children in whom calcified lesions were found is shown in Table III. From the age of two onwards the incidence of calcification increased progressively with the years, as also did the incidence of positive tuberculin tests among the children tested. Table IV shows that contact children, of whom a higher percentage were tuberculin-positive at all ages than were noncontacts (Thompson, 1947) also exhibited a higher incidence of calcification-8.2 per cent of 1,050 cases (12.0 per cent of 691 radiographed) compared with 5.2 per cent of 426 cases (5.4 per cent of 409 radiographed). As only those with a negative tuberculin-test were not radiographed, there is no reason to suppose that any significant number of calcified lesions was missed.

\section{SUMMARY}

Calcified lesions in the lung or intrathoracic lymph nodes were found in children in Ealing, Middlesex, to be accompanied almost always by skin reactivity to tuberculin. Such lesions were more frequent in children known to have been in contact with tuberculosis, and the incidence of them increased in successive age groups, along with a progressive incidence of positive tuberculinreactions in children generally.

The character of these lesions was that of the tuberculous primary complex. Pulmonary nodules were usually single, and commoner on the right than on the left side but otherwise equally distributed throughout the lung field.

In the population concerned, intrathoracic calcification indicates per se a past tuberculous infection, partly healed but not necessarily obsolete.

\section{REFERENCES}

Blacklock, J. W. S. (1936). Brit. med. J., 2, 324.

Brailey, M. (1937). Bull. Johns Hopk. Hosp., 61, 258.

Christie, A., and Petersen, J. C. (1945). Amer. J. publ. Hith., 35, 1131.

Feldman, W. H., and Helmholz, H. F. (1945). Amer. J. Dis. Childh., 70, 201.

High, R. H., Zwerling, H. B., and Furcolow, M. L. (1947). Publ. Hlth. Rep., Wash., 62, 20.

Palmer, C. E. (1945). Publ. Hith. Rep., Wash., 60, 513. Rich, A. R. (1944). "The Pathogenesis of Tuberculosis," Baltimore.

Thompson, B. C. (1947), Arch. Dis. Childh., 22, 1. 